\title{
A Case of Giant Leiomyosarcoma of the Rectum
}

\author{
NAOFUMI ERIGUCHI, SHIGEAKI AOYAGI, MASAO HARA, \\ EIJI TANAKA AND MITSUO HASHIMOTO
}

Department of Surgery, Kurume University School of Medicine, Kurume 830-0011, Japan

\begin{abstract}
Summary: A 63 year-old-man was admitted to our hospital with the chief complaint of dyschezia. Digital examination revealed a large solid mass on the posterior wall of the rectum. Endoscopically, the tumor was covered by an intact mucosal layer. Under the diagnosis of rectal leiomyosarcoma, abdominoperineal resection of the rectum was performed. The tumor was $10 \times 9 \times 8 \mathrm{~cm}$ in size, and its cross section showed a gray-white tumor with central necrosis. Microscopically, the large tumor of the rectum was mainly located in the proper muscle layer and adventitia, and showed cellular proliferation of spindle-shaped and mild pleomorphic stromal cells, arranged in interlacing fashion, and focal necrosis. The histologic findings support the diagnosis of leiomyosarcoma. Leiomyosarcoma of the rectum is a relatively uncommon disease. We report our case with reference to the literature.
\end{abstract}

Key words leiomyosarcoma, rectum, large tumor

\section{INTRODUCTION}

Leiomyosarcoma of the rectum is a rare entity and represents fewer than $0.5 \%$ of all rectal tumors [1]. Since Exner [2] presented the first two cases of the smooth muscle tumor in 1908, approximately 215 cases of leiomyosarcoma of the rectum have been reported. The present case of leiomyosarcoma is reported in order to demonstrate the importance of abdominal computed tomography (CT), magnetic resonance imaging (MRI) and endorectal ultrasound (EUS) in the diagnosis of leiomyosarcoma.

\section{CASE REPORT}

A 63-year-old man was admitted to our hospital with the chief complaint of one month history of dyschezia. Digital rectal examination revealed a rectal mass $3-4 \mathrm{~cm}$ from the anal edge. The physical examination was otherwise negative. Laboratory tests, including blood count, electrolytes, urine analysis, and sedimentation rate, were all normal. Barium enema examination showed a non-occluding mass 3-4 cm from the anal edge (Fig. 1a). Recto- sigmoidoscopy confirmed the diagnosis, showing a tumor covered by an intact mucosal layer at the described site. Using an ultrasound transducer scanning in a $90{ }^{\circ} \mathrm{C}$ angle to the rectal access with a focus length of $3-5 \mathrm{~cm}$, the endorectal ultrasonographic image differed completely from the usual appearance of rectal carcinoma. Abdominal CT and MRI revealed a large low density lesion with extracanalicular growth from the lower rectum to the upper rectum (Fig. 1b,c). Under general anesthesia, an abdominoperineal resection of the tumor was performed, and there were no findings of liver metastases nor perineal dissemination. A $10 \times 9 \times 8$ $\mathrm{cm}$ tumor of the rectum was excised (Fig. 2). All lymph nodes were negative for metastases. Microscopic examination showed large tumor which was mainly located in the proper muscle layer and adventitia, and cellular proliferation of spindleshaped and mild pleomorphic stromal cells, arranged in interlacing fashion (Fig. 3).

The large tumor was diagnosed as a leiomyosarcoma with over 10 mitotic features encountered per 10 high power fields. Postoperatively, the patient had an uneventful recovery, and no evidence of 

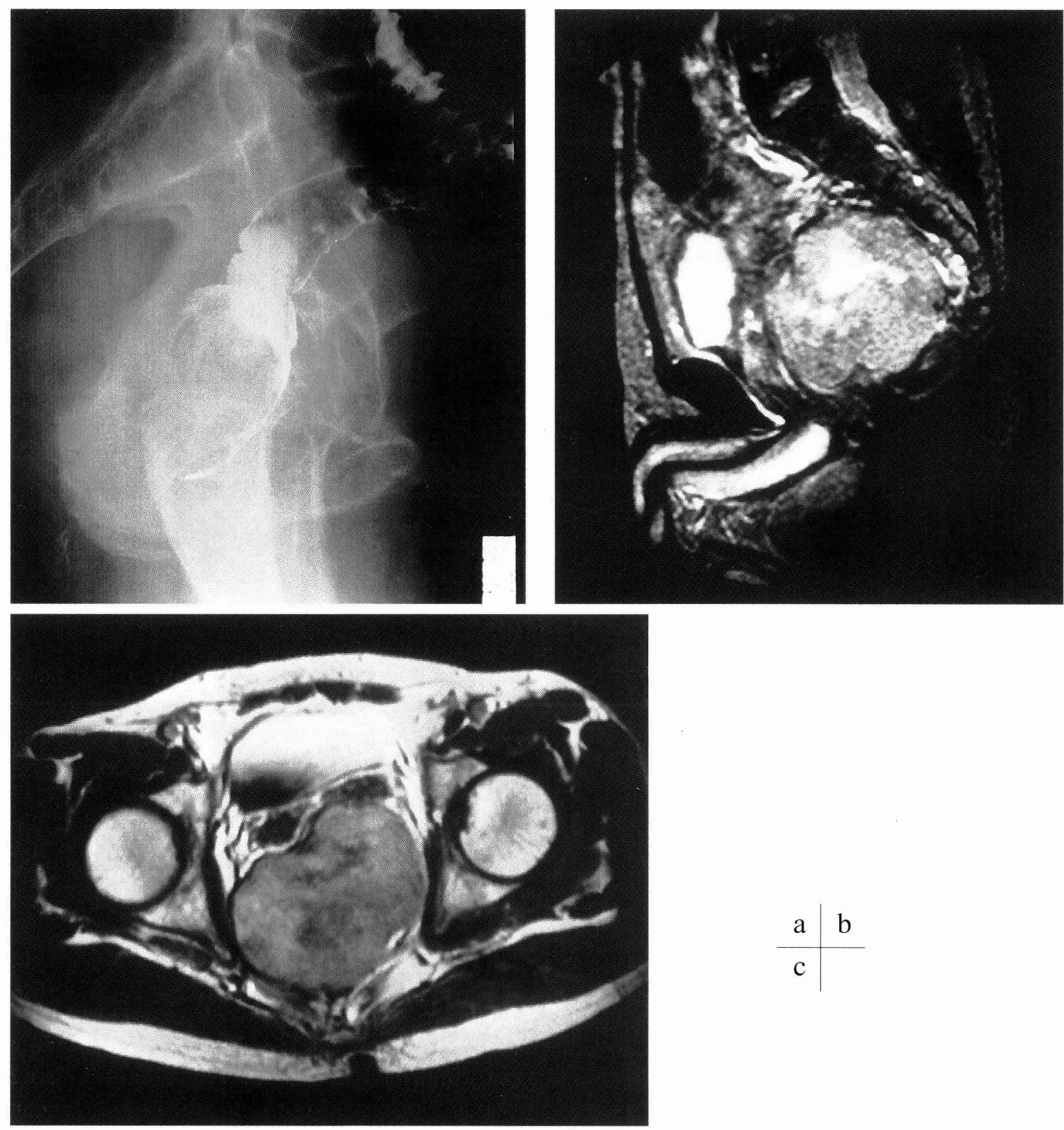

Fig. 1a. Barium enema revealed a filling defect in the rectum.

1b,c. MRI and CT showing large pelvic mass.

recurrence is present at this time.

\section{DISCUSSION}

Leiomyosarcoma is the most common nonepithelial gastrointestinal malignancy [1]. It occurs frequently in the stomach, followed by small bowel and, less commonly, the large intestine. Primary leiomyosarcoma of the rectum is a very uncommon neoplasma. The true incidence is unknown, but approximately $0.1-0.3 \%$ of all colorectal malignancies are leiomyosarcomas [3]. Kahlifa et al. [4] reported an incidence $0.07 \%$ of 8881 tumors of the rectum. A review from the Mayo Clinic showed a total of 108 cases of primary intestinal leiomyosarcomas over a period of 25 years, and about $6 \%$ of 


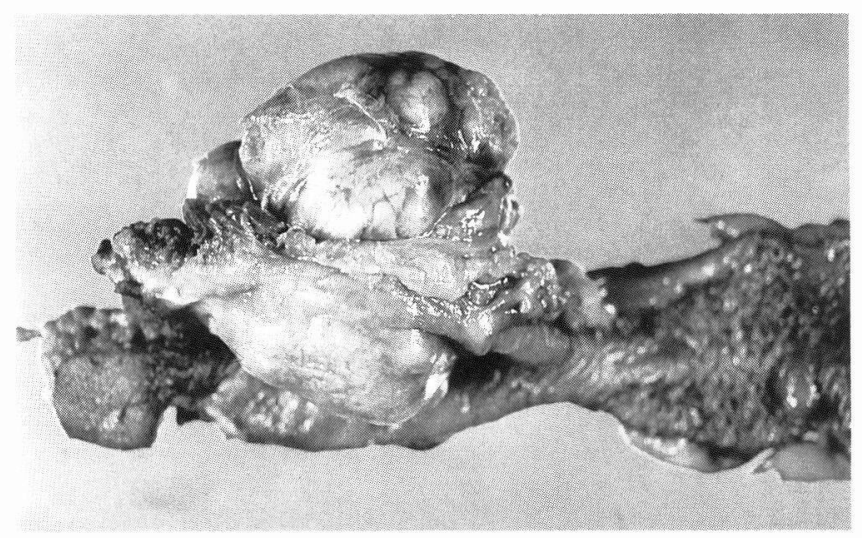

(a)

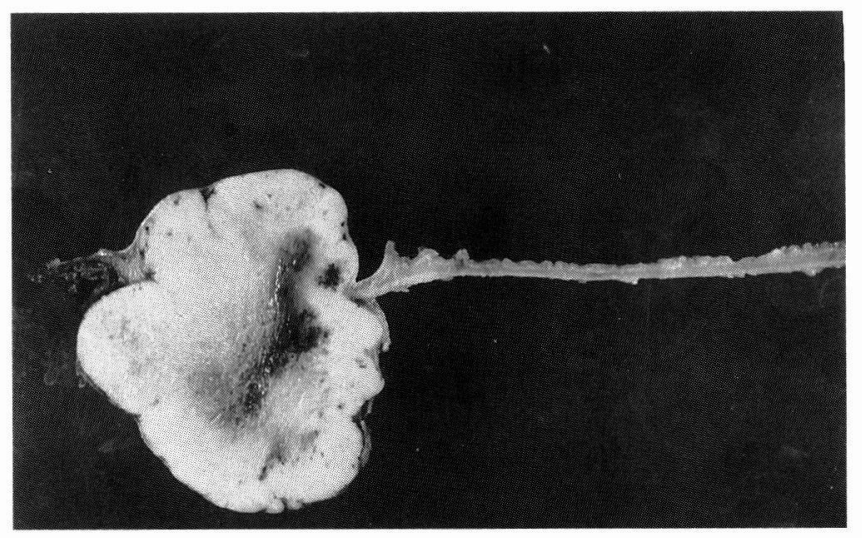

(b)

Fig. 2. Macroscopic findings of the resected specimen. The tumor with extracanalicular growth, measuring $10 \times 9 \times 8 \mathrm{~cm}$ in size, was located from the upper rectum to lower rectum (a). The cut surface was uniformly soft and with hemorrhage or necrosis. This mass extended into the perirectal fat but retained a circumscribed margin (b).
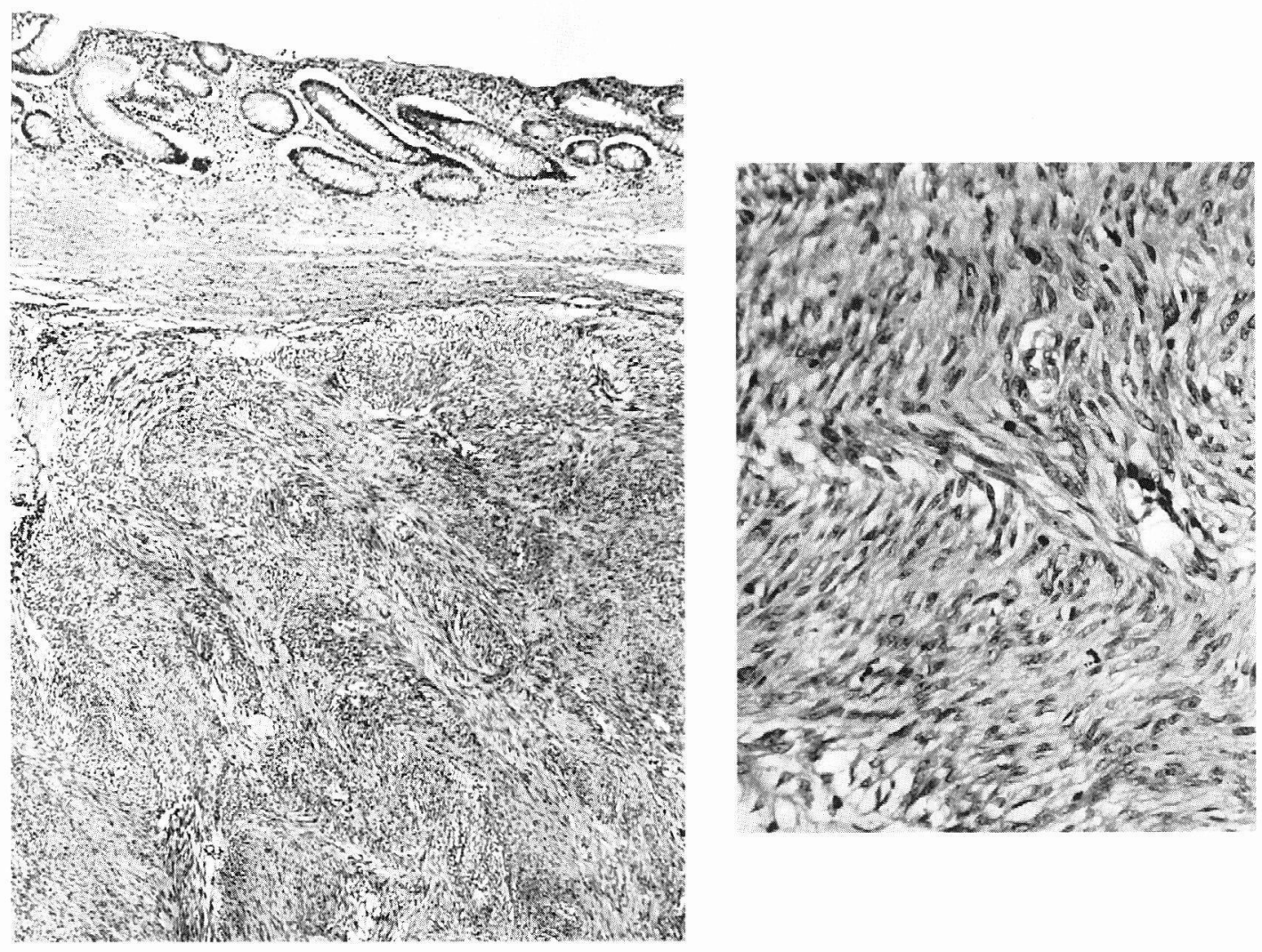

Fig. 3. Histological findings of the resected specimen shows interlacing bundles of spindle-shaped tumor cells.

these cases occurred in the anorectal region [1]. Since 1992, there were four cases of over $10.0 \mathrm{~cm}$ in size reported in the Japanese literature (Table 1) [58]. The average age in these cases was 69.4 years, with a ratio of 3 men to 2 women, or $1.5: 1$. The principal symptoms in these cases were anal bleeding and anal pain. All patients were treated by abdominoperineal resection. Liver metastasis occurred in two patients. About $80 \%$ of the rectal leiomyosarcomas are located in the lower third and 
TABLE 1

Reported cases of large leiomyosarcoma of the rectum in Japan (from 1992)

\begin{tabular}{|c|c|c|c|c|c|c|c|c|}
\hline No & Author & & Age & Sex & Chief complaint & Size of tumor $(\mathrm{cm})$ & Procedure & Outcome \\
\hline 1 & Kanzaki & '92 $92^{5]}$ & 69 & $\mathrm{~F}$ & anal pain and bleeding & $12 \times 9 \times 7$ & Miles op & \\
\hline 2 & Okuda & $93^{6]}$ & 63 & M & anal bleeding & $16 \times 19 \times 7$ & pelvic exenteration & 4M alive \\
\hline 3 & Sagawa & '96 & 67 & M & anal bleeding & $13 \times 12$ & Miles op & $1 \mathrm{Y} 11 \mathrm{M}$ died liver meta. \\
\hline 4 & Ishida & $96^{8]}$ & 81 & $\mathrm{~F}$ & abnormal defecation & $10 \times 8 \times 6$ & Miles op & $11 \mathrm{M}$ died lievr meta. \\
\hline 5 & Author & ’97 & 67 & M & dyschezia & $10 \times 9 \times 8$ & Miles op & $12 \mathrm{M}$ alive \\
\hline
\end{tabular}

can be easily detected by the examining finger [4]. Usually, they grow into the lumen but may also develop intramurally or exocolically. The perineal area may allow tumors to grow without producing signs and symptoms early in its course. The abdominal CT and MRI are extremely helpful to better delineate the size and invasiveness of these masses. Endosonography can provide exact assessment of tumor size and expansion and is of great value in selecting the appropriate treatment [9]. Leiomyosarcomas do not tend to spread through lymphatic channels. When metastasis occurs, the route of spread is like all sarcomas predominantly hematogenous to the liver and lung. Nevertheless, lymph node metastases have also been reported $[1,10]$. Certain pathologic features are more characteristic of leiomyosarcoma, such as; 1) diameter of 5 $\mathrm{cm}$ or larger, 2) tumor cell necrosis, 3) five or more mitoses per 10 high power field, and 4) cellular atypia and cellularity. Randleman et al. [11] concluded that when the lesion is less than $2.5 \mathrm{~cm}$ in diameter and confined to the bowel wall, wide local excision is indicated. However, patients with leiomyosarcoma of the anorectal region that measure more than $2.5 \mathrm{~cm}$, or those that are not limited to the bowel wall, should be treated with a more radical surgical approach, i.e.,"abdominoperineal resection, low anterior, or pelvic exenteration." Minsky et al. [12] preferred local resection for low grade tumors and lesions less than $2 \mathrm{~cm}$ in diameter with or without subsequent high-dose radiation therapy. A review of the literature showed a recurrence rate of $86 \%$ in 53 cases of rectal leiomyosarcoma treated by local excision [3]. Recurrence after local excision has been reported to be 67.5 vs. $19.5 \%$ after abdominoperineal resection [4]. Plukker et al. [13] recommended an abdominoperineal resection particularly in cases of pararectal extension. The rationale for this policy is not only the reduced risk of local recurrence but also the fact that recurrent lesions tend to be more aggressive both clinically and histologically. So wide local excision is only recommended for small intraluminal low-grade leiomyosarcomas.

At present, this approach appears to be endorsed by most surgeons. The overall survival rate of rectal leiomyosarcoma is poor with a five year survival of $20-25 \%[3,14]$. The prognosis mostly relates to the degree of differentiation, being the worst in the highly malignant poorly differentiated type because of early dissemination of disease.

In summary, we reported a large leiomyosarcoma of the rectum. The optimal treatment for this neoplasma is not known, but the standard surgical approach is the abdominoperineal resection of the tumor. Radiation therapy seemed to offer some benefit in terms of local control [15], but offers no benefit in overall survival [16], and various chemotherapeutic trials are currently under way.

\section{REFERENCES}

1. Akwari OE, Dozois RR, Weiland LH, and Beahrs OH. Leiomyosarcoma of the small and large bowel. Cancer 1978; 42:1375-1384.

2. Exner A. Uber nichtmelanotische Sarkome des Mastdarmes. Med Klin 1908; 4:858-861.

3. Diamante $\mathrm{M}$, and Bacon HE. Leiomyosarcoma of the rectum; report of a case. Dis Colon Rectum 1967; 10:347-351.

4. Khalifa AA, Bong WL, Rao VK, and Williams MJ. Leiomyosarcoma of the rectum: report of a case and review of the literature. Dis Colon Rectum 1986; 29:427432.

5. Kanzaki N, Asagawa T, Morino Y, Miyai Y, Suzuki Y et al. A case of rectal leiomyosarcoma. Clinical Imagiology 1992; 8:76-81. (in Japanese)

6. Okuda T, Iwatare J, Ono R, Kouda M, Higashi M et al. Giant rectal leiomyosarcoma, report of a case. Stomach and Intestine 1993; 28:211-214. (in Japanese)

7. Sagawa T, Kubozono T, Yano T, and Bandou Y. A case report of leiomyosarcoma of the rectum with liver metastasis. J Jpn Soc Clin Surg 1996; 57:2746-2750.

8. Ishida T, Obata M, Nagou M, Shirota Y, Kamikawa J et 
al. A case of leiomyosarcoma of the rectum. Geka Shinryo 1996; 9:1105-1109. (in Japanese)

9. Wolf O, Glaser F, Kuntz C, and Lehnert T. Endorectal ultrasound and leiomyosarcoma of the rectum. Clin Investig 1994; 72:381-384.

10. Walsh TH, and Mann CV. Smooth muscle neoplasmas of the rectum and anal canal. Br J Surg 1984; 71:597-599.

11. Randleman Jr CD, Wolff BG, Dozois RR, Spencer RJ, Weiland LH et al. Leiomyosarcoma of the rectum and anus: a series of 22 cases. Int J Colorect Dis 1989; 4:9196.

12. Minsky BD, Mies C, and Rich TA. Leiomyosarcoma of the anus treated with sphincter-preserving surgery and radiation therapy. J Surg Oncol 1986; 32:89-91.
13. Plukker JT, Blomjous EM, Wagstraff J, and Meijer S. Primary leiomyosarcoma of the rectum; report of two cases and review of the literature. Neth J Surg 1989; 41:88-91.

14. Eitan N, Auslander L, and Cohen Y. Leiomyosarcoma of the rectum: reports of three cases. Dis Colon Rectum 1978; 21:444-446.

15. Rice JP, MacGillivray DC, Sharpe RW, Weiser EB, and Ghosh BC. Case report: perineal leiomyosarcoma. Gynecol Oncol 1990; 37:132-137.

16. Glenn J, Sindelar WF, and Kinsella T. Result of multimodality therapy of respectable soft-tissue sarcomas of the retroperitoneum. Surgery 1985; 97:316-325. 